WE4B-4

\title{
Monolithic 40-GHz 670-mW HBT Grid Amplifier
}

\author{
Cheh-Ming Liu, Emilio A. Sovero, Wu Jing Ho, J. A. Higgins, Michael P. De Lisio, and David B. Rutledge
}

\begin{abstract}
A 36-element monolithic grid amplifier has been fabricated. The active elements are pairs of heterojunction-bipolar-transistors. Measurements show a peak gain of $5 \mathrm{~dB}$ at $40 \mathrm{GHz}$ with a 3-dB bandwidth of $1.8 \mathrm{GHz}(4.5 \%)$. Here we also report comparisons of patterns and tuning curves between the measurements and theory. The grid includes base stabilizing capacitors which result in a highly stable grid. The maximum saturated output power is $670 \mathrm{~mW}$ at $40 \mathrm{GHz}$ with a peak power-added efficiency of $4 \%$. This is the first report of power measurements on the monolithic quasi-optical amplifier.
\end{abstract}

\section{INTRODUCTION}

A grid amplifier is a spatial power-combining device that amplifies a microwave beam and combines the outputs of many transistors, making it possible to greatly increase power [1-3]. Combining the power in free space, grid amplifiers eliminate losses associated with waveguides and transmission-line networks. Grid amplifiers have demonstrated gains of 10 and $11 \mathrm{~dB}$ at $10 \mathrm{GHz}$ with HBT's [1,2], and $12 \mathrm{~dB}$ at $9 \mathrm{GHz}$ with pHEMT's [3]. Other spatial-power combining approaches are actively being pursued [4-9]. Recently, Higgins, Sovero and Ho demonstrated a monolithic Q-band plane-wave amplifier using slot and patch antennas [10]. Based on the gain and stability models of the hybrid grid amplifiers $[2,3]$, we reported monolithic HBT and pHEMT grid amplifiers $[11,12]$. In this paper, we report additional measurements on the monolithic HBT grid amplifier, including gain, tuning curves, patterns, and power measurements. The grid has a $5-\mathrm{dB}$ gain and $670-\mathrm{mW}$ saturated output power at $40 \mathrm{GHz}$.

The monolithic grid amplifier, shown in Fig. 1, is composed of 36 unit cells on a $565-\mu$ m thick GaAs substrate. There are 6 elements on each side. The length is $12 \mathrm{~mm}$ on one side. The grid was fabricated with the HBT process established at Rockwell International [13]. The maximum available gain of an individual transistor at $40 \mathrm{GHz}$ is $9 \mathrm{~dB}$.

Manuscript submitted February 22, 1996. This research was supported by the Air Force Material Command/Rome Laboratory, ARPA Contract \#F30602-93-C-0183, and the Army Research Office.

C.-M Lin, M.P. De Lisio and D.B. Rutledge are with the Division of Engineering and Applied Science, California Institute of Technology, Pasadena, CA, 91125.

E.A. Sovero, W.J. Ho, and J.A. Higgins are with the Science Center, Rockwell International Corporation, 1049 Camino Dos Rios, Thousand Oaks, CA 91385.

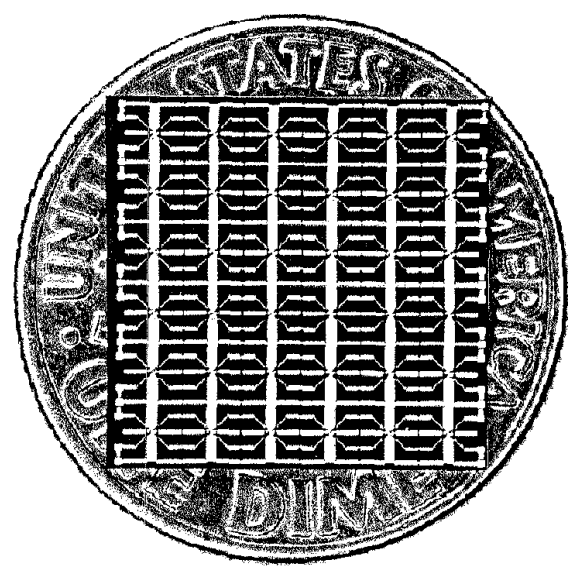

Fig. 1. Photograph of the 36-element monolithic grid amplifier compared with a dime. The chip is $12 \mathrm{~mm}$ on each side.

\section{DESIGN}

The unit cell is shown in Fig. 2. The period of the unit cell is $1.9 \mathrm{~mm}$. In the unit cell, the input leads receive the horizontally-polarized input beam. The input matching capacitor cancels the inductive reactance of the input lead. The stabilizing capacitor prevents commonmode oscillations. The output leads radiate the output beam with vertical polarization.

The grid-amplifier system(Fig. 3a), can be represented by an equivalent-circuit model(Fig. 3b) [2]. The input beam is on the left-hand side with horizontal polarization. The input beam is received by the amplifier grid amplified, and then reradiated with vertical polarization, as the output beam to the right. The unit cell links the input and output. The polarizers confine the signal path from the left, input with horizontal polarization, to the right, output with vertical polarization. The matching conditions are determined by the polarizers and tuning slabs.

At $40 \mathrm{GHz}$, the HBT input impedance for the maximum available gain is $8+j 5.5 \Omega$. It is important to match the input because the resistive part of the corresponding input impedance is much lower than the freespace impedance. To match the input, the GaAs substrate acts as a quarter-wavelength transformer.

In previous grid amplifiers, common-mode oscillations were observed [2,3]. Hence stability is an important issue in the design. Based on the stability analysis in [2], if stabilizing capacitors are not included, we predict the grid 


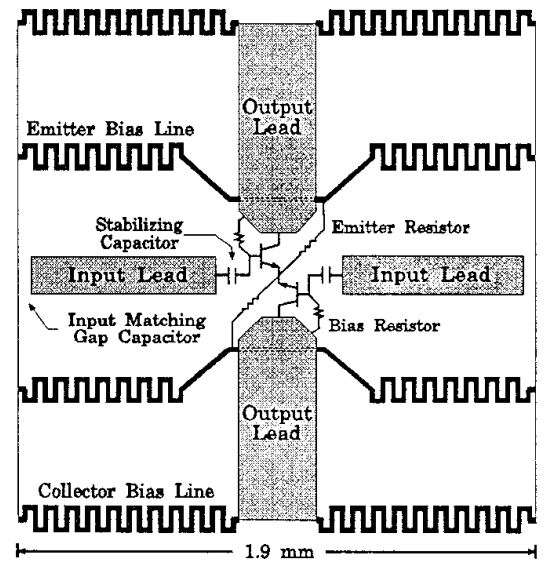

Fig. 2 The unit cell. The input leads are $120 \mu \mathrm{m}$ wide and the output leads are $300 \mu \mathrm{m}$ wide. The width of the input matching gap is $30 \mu \mathrm{m}$. The stabilizing capacitor is $27 \mathrm{fF}$. The bias resistors are $4 \mathrm{k} \Omega$ and the emitter resistors are $150 \Omega$ The width of the meandering bias line is $20 \mu \mathrm{m}$.

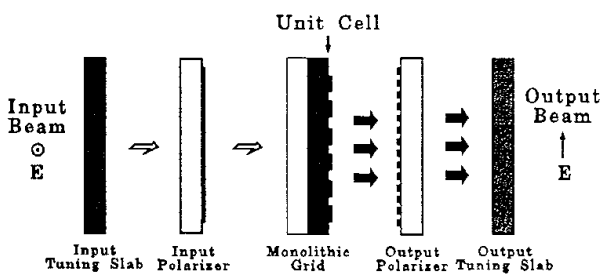

(a)

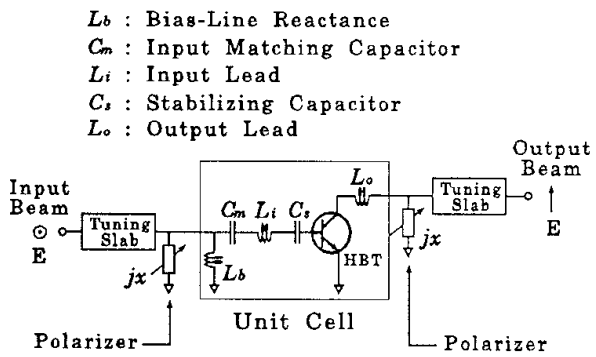

(b)

Fig. 3 (a) Cross-section of the grid amplifier. The input beam, with horizontal polarization, is fed from the left. The output beam, with vertical polarization, is measured on the right. (b) Equivalent-circuit model

will oscillate at $22 \mathrm{GHz}$. With the stabilizing capacitors, the grid is stable with a phase margin of 58 degrees and a gain margin of $6.6 \mathrm{~dB}[11]$.

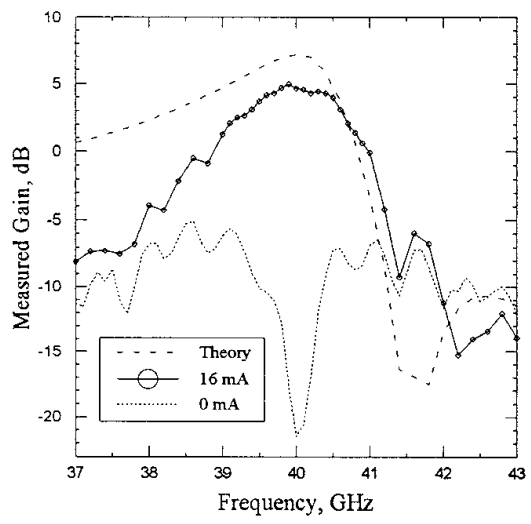

Fig. 4 Gain measurements. The peak gain is $5 \mathrm{~dB}$ at $40 \mathrm{GHz}$ The $3-\mathrm{dB}$ bandwidth is $1.8 \mathrm{GHz}(4.5 \%)$. The theory is calculated from the transmission-line equivalent-circuit model [2].

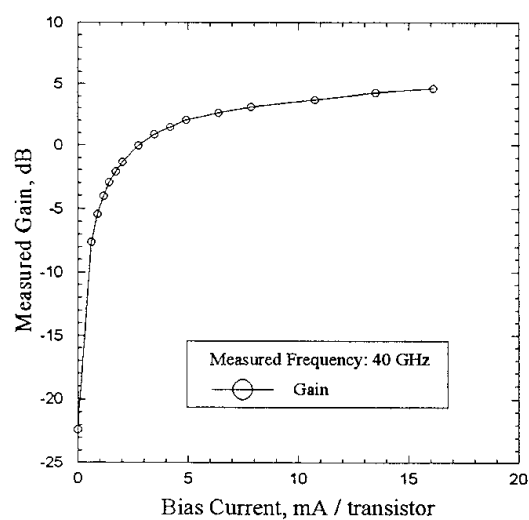

Fig. 5 Gain versus bias current at $40 \mathrm{GHz}$. The peak gain is $5 \mathrm{~dB}$ at $16 \mathrm{~mA}$ per transistor. The on-off ratio is $27 \mathrm{~dB}$.

\section{GAIN}

The gain is measured in the far-field [1]. Due to the high DC dissipation, the grid was biased for only 0.6 seconds at a time to avoid thermal damage. The gain response, from 37 to $43 \mathrm{GHz}$ as shown in Fig. 4, has a peak gain of $5 \mathrm{~dB}$ at $40 \mathrm{GHz}$ and 3 -dB bandwidth of $1.8 \mathrm{GHz}(4.5 \%)$. Fig. 5 shows the gain versus the bias current at $40 \mathrm{GHz}$. The gain inceases monotonically from $-22 \mathrm{~dB}$ to $5 \mathrm{~dB}$ as the bias current increases from 0 to $16 \mathrm{~mA}$ per transistor. The difference between biased and zero-biased gains is $27 \mathrm{~dB}$ at $40 \mathrm{GHz}$. No oscillation was observed-the grid is highly stable. 


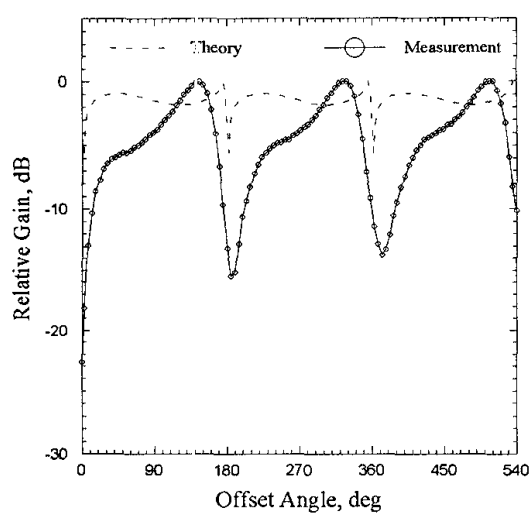

Fig. 6 Relative gain a $t 40 \mathrm{GHz}$ as a function of output polarizer position.

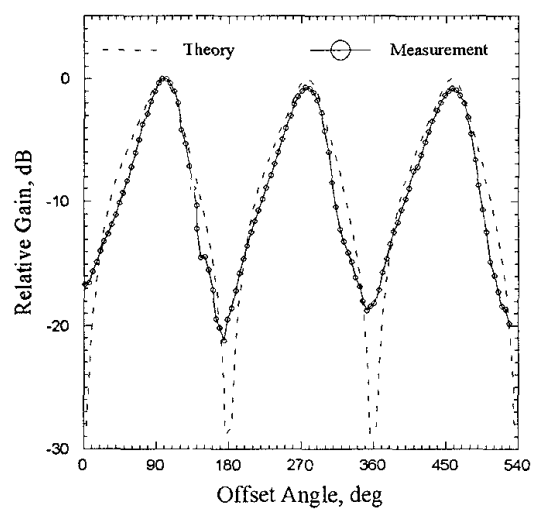

Fig. 7 Relative gain at $40 \mathrm{GHz}$ as a function of input polarizer position.

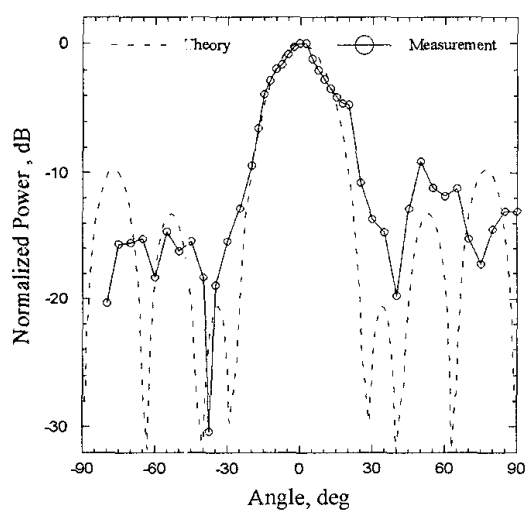

Fig. 8 Ontput H-plane radiation pattern at $40 \mathrm{GHz}$.

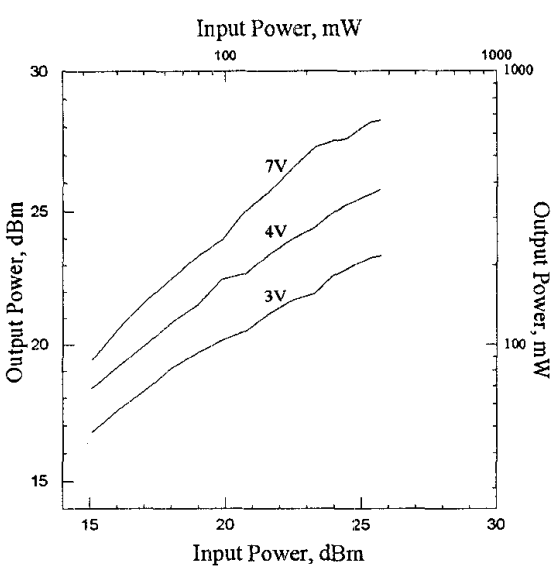

Fig. 9 Output power versus input power at $40 \mathrm{GHz}$, The peak output power is $670 \mathrm{~mW}$ at $7 \mathrm{~V}$.

\section{Tuning and Pattern}

Fig. 6 and Fig. 7 show input and output tuning curves at $40 \mathrm{GHz}$. The tuning curves are plots of the gains versus the polarizer positions. The measured input-tuning curve is different from the theoretical one. This may be due to the critical matching condition at the input. However, the measured output-tuning curve matches to the theory well.

The output H-plare radiation pattern is shown in Fig. 8. This pattern is measured by fixing the grid amplifier and the input antenna, and rotating the output antenna. The theoretical pattern of six elementary dipoles with a mirror $8.5-\mathrm{mm}$ behind is also shown in Fig. 8 . The measurement shows reasonable match to the theory in the main lobe

\section{POWER}

In the power measurement, we used a 10-W Ka-band Traveling-Wave Tube(TWT) amplifier as the source. The power was measured in the far field at $40 \mathrm{GHz}$. Fig. 9 shows the output power versus the input power of the grid amplifier at three bias levels. The peak output power is $670 \mathrm{~mW}$ at $7 \mathrm{~V}$ with the bias current of $16 \mathrm{~mA}$ per transistor. Fig. 10 shows the gain and power-added efficiency versus the input power. The gain drops to $2.5 \mathrm{~dB}$ at the maximum output power. The peak effciency is $4 \%$ with $500-\mathrm{mW}$ output power. At $7 \mathrm{~V}, 70 \%$ of the DC power is actually dissipated in the bias lines and emitter resistors.

\section{CONCLUSION}

We have demonstrated a 36-element monolithic HBT grid amplifier. Based on the gain and stability models, the result is a highly stable grid amplifier. The grid has a 5 - $\mathrm{dB}$ gain at $40 \mathrm{GHz}$ with $4.5 \% 3$-dB bandwidth. The 


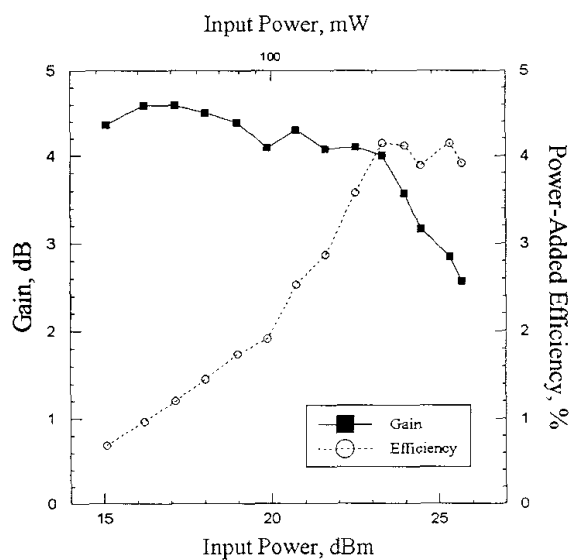

Fig. 10 Gain and power-added efficiencies versus input power at $40 \mathrm{GHz}$. The gain at maximum output power is $2.5 \mathrm{~dB}$. The peak grid efficiency is $4 \%$.

maximum measured output power is $670 \mathrm{~mW}$ with $4 \%$ power-added efficiency at $40 \mathrm{GHz}$.

\section{REFERENCES}

[1] M. Kim, E. Sovero, J. Hacker, M. De Lisio, J.-C. Chiao, S. Li, D. Gagnon, J. Rosenberg, and B. Rutledge, "A 100-Element Grid Amplifier," IEEE Trans. Microwave Theory Tech., MTT-41, pp. 1762-1771, October 1993.

[2] C.-M. Liu, E. Sovero, M. De Lisio, A. Moussessian, J. Rosenberg, and D. Rutledge, "Gain and Stability Models for HBT Grid Amplifiers," 1995 IEEE AP-S Int. Symp. Dig., pp.1292-1295, 1995

[3] M. De Lisio, S.W. Duncan, D.-W. Tu, C.-M. Liu, A Moussessian, J. Rosenberg, and D. Rutledge, "Modelling and Performance of a 100-Element pHEMT Grid Amplifier," submitted to IEEE Trans. Microwave Theory Tech, 1995.

[4] H.-S. Tsai, M.J.W. Rodwell, and R.A. York "Planar Amplifier Array with Improved Bandwidth Using Folded-Slots," IEEE Microwave and Guided Wave Letters, MGWL-4, pp.899-901, May 1994.

[5] J. Benet, A. Perkons, S. Wong, and A. Zaman, "Spatial Power Combining for Millimeter-wave Solid State Amplifier," IEEE MTT-S Int. Microwave Symp. Dig., pp. 619-622, 1993.

[6] T. Mader, J. Schoenberg, L. Harmon, and Z. Popovic, "Planar MESFET Transmission Wave Amplifier " Elec tronic Lett., vol. 29, pp. 1699-1701, September 1993.

[7] N. Sheth, T. Ivanov, A. Balasubramaniyan, and A. Mortazawi, "A Nine HEMT Spatial Amplifier," IEEE
MTT-S Int. Microwave Symp. Dig., 1994, pp. $1239-$ 1242

[8] "Quasi-Optical Power Combining Techniques," Robert York, in Millimeter and Microwave Engineering for Communications and Radar, J.Wiltse, editor, Critical Reviews of Optical Science and Technology, vol. 54, pp. 63-97, 1994.

[9] J. Hubert, J. Schoenberg, and Z. Popovic, "HighPower Hybrid Quasi-Optical Ka-Band Amplifier Design," IEEE MTT-S Int. Microwave Symp. Dig., 1995, pp. $585-588$.

[10] J.A. Higgins, E.A. Sovero, and W.J. Ho, " $44-\mathrm{GHz}$ Monolithic Plane Wave Amplifiers," IEEE Microwave Guided Wave Lett., MGWL-5, pp.347-348, October 1995.

[11] C.-M. Liu, E. Sovero, W.-J. Ho, J.A. Higgins, and D. Rutledge, "A Millimeter-Wave Monolithic Grid Amplifier," Int. Journal of Infrared and Millimeter Waves , pp. 1901-1910, Vol. 16, November 1995.

[12] M. De Lisio, S.W. Duncan, D.-W. Tu, S. Weinreb, C. M. Liu, and D. Rutledge, "A 44-60 GHz Monolithic pHEMT Grid Amplifier," to be presented in the 1996 IEEE MTT-S Int. Microwave Symposium.

[13] P. Asbeck, F. Chang, K.-C. Wang, G. Sullivan, D. Cheung, "GaAs-Based Heterojunction Bipolar Transistors for Very High Performance Electronic Circuits," Proceedings of the IEEE, vol. 18, pp. 1709 1726, December 1993. 